\title{
Loss Aversion in Post-Sale Purchases of Consumer Products and their Substitutest
}

\author{
By Debajyoti Ray, Matthew Shum, and Colin F. Camerer*
}

Loss aversion is the disproportionate distaste for subjective losses, compared to equal-sized subjective gains. It was originally discovered in laboratory choices among monetary risks (Kahneman and Tversky 1979), but has since become evident in allocations, behavior, and institutional rules in many markets. As one example, Thaler (1980) was the first to conjecture that people would be reluctant to buy consumer goods at a price above a "reference price," due to disutility from the subjective loss of paying more than a reference price. (Consumer backlash about the car service Uber's modern "surge pricing" during demand shocks is a potential illustration.) Not long after Thaler's conjecture, Putler (1992) reported corroborating evidence that elasticities of demand for eggs were about twice as high for price increases $(-0.78)$ than for decreases $(-0.33)$, consistent with pricing reference-dependence and loss aversion.

As with many initial empirical results reported in behavioral economics, the surprising early evidence of asymmetry in price elasticities inspired many alternative explanations extending rational choice explanations. In the case of elasticity asymmetries, consumer heterogeneity is an obvious plausible alternative (Bell and Lattin 2000). However, careful estimation in marketing science in the last two decades, using high-quality choice data from supermarket scanner panel data, shows substantial consumer loss aversion toward price changes of the kind Putler (1992) first documented, even when alternative

\footnotetext{
* Ray: Independent. 4500 Via Marina, Marina del Rey, CA 90292 (e-mail: debray@gmail.com); Shum: HSS Caltech 228-77, 1200 E. Calif. Blvd., Pasadena, CA 91125 (e-mail: mshum@hss.caltech.edu); Camerer: HSS Caltech 228-77, 1200 E. Calif. Blvd., Pasadena, CA 91125 (e-mail: camerer@hss.caltech.edu). Thanks to HSS and the BNDF for support.

${ }^{\dagger}$ Go to http://dx.doi.org/10.1257/aer.p20151037 to visit the article page for additional materials and author disclosure statement $(\mathrm{s})$.
}

explanations including heterogeneity can be ruled out.

Loss averse consumers make substantially more purchases when prices are discounted against their reference price, and make disproportionately fewer purchases when prices are increased. However, this dynamic pattern does not uniquely identify loss aversion as the cause of this behavior (loss aversion simply magnifies the drop in demand after a sale, compared to a reference-independent model). A sensible alternative explanation is that opportunistic buyers who anticipate their future demands "stockpile" items that are on sale temporarily (see Bell, Chiang, and Padmanabhan 1999). When the sale is over, demand is temporarily dried up because price-sensitive consumers have already stocked up on the goods they want most.

We test a new prediction of the reference-dependent pricing model that cannot be attributed to stockpiling. We call this the "substitution effect." If reference prices influence sales, then the relative value of a product, once it is no longer on sale, will go down in comparison to a substitute product which did not experience a similar sale period. Reference-dependent consumers will then buy less of the post-sale product and will buy (relatively) more of substitute products. The change in relative sales of a product, post-sale, and its substitutes can therefore provide information about the extent of reference-dependence in consumer buying.

A closely related phenomenon called "regret devaluation," has been described in psychology (Arkes, Kung, and Hutzel 2002). Regret devaluation occurs when passing up an initial choice decreases the likelihood that the same choice will be made later, on less valuable terms which are still marginally beneficial. Inaction due to regret devaluation is obviously an economic error because it lets previous history influence a cost-benefit calculation that should only be forward-looking. Tykocinski and Pittman (2001) 
showed this effect experimentally for post-sale product non-purchase in hypothetical consumer choice. Stock investors also tend to deliberately not repurchase stocks they have sold, after a subsequent capital gain (Weber and Welfens 2011 and Frydman and Camerer 2014). Our study applies the field-data approach from the latter stock market domain to the consumer domain, for which no field data have yet been reported.

\section{Data}

Our full dataset includes online sales records for a large retailer of hardware and household products, over a period of 222 days from April 29, 2011 to December 6, 2011. A total of 6,039 items were available, generating $\$ 40.6$ million in sales over 2.18 million units sold. Most items are frequently discounted, and the best-selling items are discounted most often.

A crucial step in measuring the substitution effect is defining which products are substitutes. In standard theory, substitutes are products which have positive price cross-elasticity (i.e., a price increase in one product increases sales of its substitute). However, this elasticity-based measure seems to work surprisingly poorly in our data. A simple inspection of product pairs which have large cross-price elasticities shows many which are just as implausible as substitutes, perhaps due to the large number of SKUs, to daily variability, or to omitted variables. 1

Therefore, we obtained a list of the top 100 selling products and their perceived substitutes from the retailer. This list is typically used by the retailer to present similar items during a web search on the retailer's site for a particular product. Upon closer inspection of this list, we removed a handful of product pairs which were clearly not substitutes, resulting in a total of 204 pairs of substitutable goods. Only 65 of the top 100 items had clear substitutes, with a maximum of 11 substitutes for one of the items. Each item on average had about three substitutes. In what follows, we will refer to each such pair of products as a "substitute pair," and use the terminology "good A" to denote the main good which

\footnotetext{
${ }^{1}$ We computed the cross-elasticity of the top selling SKU, "45 Watt Solar Panel," against the top 1,000 SKUs. The two SKUs that had the highest cross-elasticity score were: "6-inch Digital Calipers" and "1,200 lb. capacity air motorcycle lift."
}

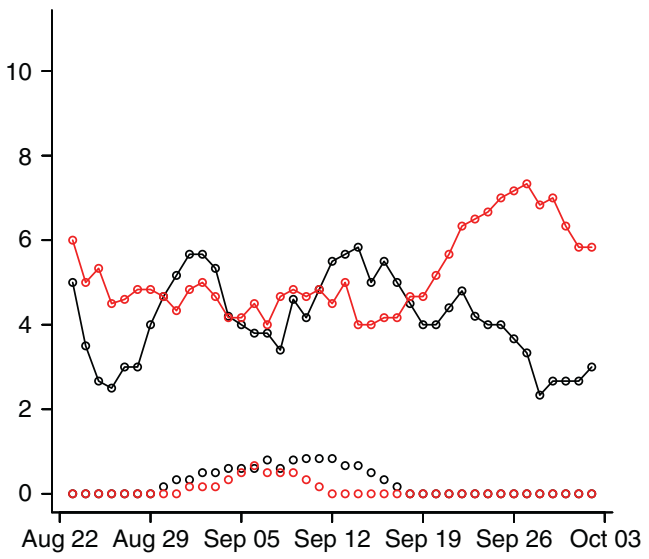

Figure 1. Example of Substitution Effect: Sales of \$50 Gift Cards InCrease after Discount PERIOD For \$100 Gift CARDS ENDS

was on sale, and "good B" to denote the substitutable good.

We show an illustrative example of the substitution effect in Figure 1 of the sale of two substitute products: $\$ 50$ and $\$ 100$ gift cards. The dots at the bottom of the graph indicate discount periods for $\$ 100$ and $\$ 50$ gift cards (in black and gray, respectively). Sales of the gift cards are plotted in the top portion of the graph. As expected, the sales of $\$ 100$ gift cards (in black) increase when a discount is offered and go down once the discount is over (on September 18). More interestingly, once the discount period ends, sales of \$50 gift cards (in gray) go up.

\section{Estimation}

We use a simple logit model of the choice between the two goods in a substitute-pair. Our model is motivated by a simple model of consumer decision-making. The utility from good $\mathrm{A}$ is given by

$$
\begin{aligned}
u_{A}= & v_{A}-\alpha p_{A}-(\lambda-1) \times\left(p_{A}-p_{r e f}\right) \\
& \times I\left(p_{A}, p_{r e f}\right)+\epsilon_{A},
\end{aligned}
$$

where $I(p, q)$ is a $0-1$ indicator function that takes the value of one if $p>q$ and zero otherwise.

The utility from the substitute good B is

$$
u_{B}=v_{B}-\alpha p_{B}+\epsilon_{B} .
$$


We assume that the $\epsilon \mathrm{S}$ are independently extreme value distributed. Then the choice probability for good A is a familiar logit expression. Using the value and price differences $v^{*}=v_{A}-v_{B}$ and $p^{*}=p_{A}-p_{B}$, then

$$
\begin{aligned}
\operatorname{Pr}(A)= & {\left[1+\exp \left(-1 \times\left[v^{*}-\alpha p^{*}-(\lambda-1)\right]\right.\right.} \\
& \left.\left.\times\left(p_{A}-p_{r e f}\right) \times I\left(p_{a}, p_{r e f}\right)\right)\right]^{-1} .
\end{aligned}
$$

The odds ratio of purchasing A relative to B is

$$
\begin{aligned}
\operatorname{Pr}(A) / \operatorname{Pr}(B)=\exp ( & v^{*}-\alpha p^{*}-(\lambda-1) \\
& \left.\times\left(p_{A}-p_{\text {ref }}\right) \times I\left(p_{a}, p_{\text {ref }}\right)\right) .
\end{aligned}
$$

In the aggregate, the market share for good $\mathrm{A}$ is just equal to $\operatorname{Pr}(A)$. Hence, the log market share ratio of the two goods $\mathrm{A}$ and $\mathrm{B}$ is just equal to

$$
\text { (1) } \begin{aligned}
\log \left(\frac{S_{A}}{1-S_{A}}\right)= & v^{*}-\alpha p^{*}-(\lambda-1) \\
& \times\left(p_{A}-p_{r e f}\right) \times I\left(p_{a}, p_{r e f}\right) .
\end{aligned}
$$

We have run two specifications of the regression above on the 204 substitute-pairs we described above. Each observation is a "substitute-pair/day." The specifications use different histories for the trailing reference price $p_{\text {ref }}$ : (1) $p_{\text {ref }}$ is the price on the previous day; and (2) $p_{r e f}$ is the average price from the five previous days.

Results are reported in Table 1. Column 1 contains the results using the previous day's price as the reference price, while column 2 contains the results using the average price from the past five days for $p_{\text {ref }}$. Note that in equation (1), there is already a minus sign in front of $(\lambda-1)$, so that a positive coefficient for this variable in the table implies that $\lambda>1$. Moreover, in all specifications we have included substitute-pair fixed effects, to control for heterogeneity across products in our dataset. ${ }^{2}$

\footnotetext{
${ }^{2}$ Because of these fixed effects, the magnitudes of the estimated regression coefficients are not comparable across Tables 1 and 2.
}

TAble 1-Estimates of LOG-Share EQUATION FOR Product A: All Sales

\begin{tabular}{lcc}
\hline \hline Variable & $\begin{array}{c}\text { Coefficient } \\
(1)\end{array}$ & $\begin{array}{c}\text { Coefficient } \\
(2)\end{array}$ \\
\hline$p_{A}-p_{B}$ & -0.00135 & -0.00110 \\
& $(0.00018)^{* * *}$ & $(0.00018)^{* * *}$ \\
$\lambda-1$ & 0.00044 & 0.00116 \\
& $(0.00017)^{* *}$ & $(0.00019) * * *$ \\
cons $=v_{A}-v_{B}$ & 0.29062 & 0.28735 \\
& $(0.01106)^{* * *}$ & $(0.01110)^{* * *}$ \\
Observations & 22,477 & 22,049 \\
Subst.-pair FX & Yes & Yes \\
\hline
\end{tabular}

***Significant at the 1 percent level.
$* *$ Significant at the 5 percent level.
*Significant at the 10 percent level.

The results are consistent with the presence of reference-dependence and a substitution effect. The value of $\lambda$ is significantly above one (especially for the results utilizing the five-day definition of $p_{\text {ref }}$, in column 2). To interpret the magnitude, we should compare the value of $\lambda$ to that of the price coefficient $\alpha$. For the results in column 2 of Table 1, we have $\lambda-1=0.00116$, which is almost equal in magnitude to -0.00110 , the coefficient $\alpha$ on the price difference $p_{A}-p_{B}$. That is, a dollar increase in the "loss" $\left(p_{A}-p_{\text {ref }}\right)$ has about the same effect on demand for good A as a dollar increase in the price of good A.

\section{A. Behavior of Experienced Consumers}

A potential moderator of the loss aversion effect is the amount of experience customers have. Evidence from labor supply of cab drivers (e.g., Camerer et al. 1997) and ownership of condominiums (Genesove and Mayer 2001) suggests that as people acquire market experience, the effect of historical reference points is reduced.

Therefore, it is useful to measure the extent of the substitution effect depending on how active consumers are in this online market. Unique identification of 861,000 customers is available in the transaction records. The total amount of purchases by each customer shows power law characteristics, with the majority of items being purchased by a relatively small number of consumers. This customer heterogeneity enables us to separate customers into "experienced" 
and "inexperienced" buyers based on total purchases. Some of the large customers are institutions, or secondary retailers which fulfill their inventory online. We eliminate 143 customers whose total orders exceed $\$ 10,000$, and 17,800 customers whose total orders are less than $\$ 1$.

Then we split the sales data by the total sales volume in dollar amounts per customer after removing the outliers. The top 50 percent of customers had sales of $\$ 25.7$ million, while the bottom 50 percent of customers had total sales of $\$ 2.67$ million.

Table 2 shows results which include main effects and variable interactions for the top 50 percent of the consumers (the most experienced, heavy-volume buyers). The top customers have a positive interaction with the price differential $p_{A}-p_{B}$, which implies a lower price elasticity that is less negative, closer to zero. They also have a large negative interaction with the reference-dependence variable $\lambda-1$, which means they are less reference-dependent than lower-experience customers. The latter finding is consistent with some other evidence that decision experience reduces a simple kind of reference-dependence (such as the backward-looking influence of past prices specified here).

\section{Discussion}

Loss-aversion has been documented in psychology experiments and in many areas of empirical social science. Losses are always defined relative to a point of reference. We assume consumers recall a short history of previous prices to create a reference price, and are averse to subjective losses (prices higher than the reference price). This utility specification predicts (as conjectured earlier in psychology) that when a product sale ends, people will be reluctant to buy that same product post-sale, and will therefore more strongly prefer substitute products than a model without reference-dependence predicts.

We report tentative evidence of this effect using a large dataset from an online hardware retailer. The specification shows a small effect of loss aversion on post-sale purchases.

One criticism of our findings that we cannot currently address empirically is that in order for the consumers to exhibit loss aversion and prefer substitute products, they need to know past prices-including when items are put on sale and when they are removed from sale. Since we
TABLE 2-Estimates OF LOG-SHARE EQUATION FOR Product A: Top versus Bottom 50 Percent in Sales VOLUME (Experience)

\begin{tabular}{lcc}
\hline \hline Variable & Coefficient & Coefficient \\
& $(1)$ & $(2)$ \\
\hline top50 & 0.13648 & 0.11492 \\
& $(0.03497) * * *$ & $(0.03615) * *$ \\
$p_{A}-p_{B}$ & -0.01204 & -0.01052 \\
& $(0.00158) * * *$ & $(0.00164) * * *$ \\
top50 $\times\left(p_{A}-p_{B}\right)$ & 0.00980 & 0.00888 \\
$\lambda-1$ & $(0.00156) * * *$ & $(0.00162) * * *$ \\
& 0.00444 & 0.01635 \\
top50 $\times(\lambda-1)$ & $(0.00542)$ & $(0.00696) * *$ \\
& -0.00362 & -0.01200 \\
cons $=v_{A}-v_{B}$ & $(0.00543)$ & $(0.00698) *$ \\
& 0.22385 & 0.23513 \\
Observations & $(0.03499) * * *$ & $(0.03612) * * *$ \\
Subst.-pair FX & 21,492 & Yes \\
\hline
\end{tabular}

$* * *$ Significant at the 1 percent level.

**Significant at the 5 percent level.

* Significant at the 10 percent level.

only have data when a sale occurs, we are limited by the data in finding out if the consumer has actually seen the past prices before making a sale. Further exploration in our dataset, and field-to-lab experiments, should be useful moving forward.

Consumer reference dependence, even if observed in just a subset of goods, has important implications for competitive strategy, pricing, and the timing of promotions. According to prevailing theory, firms could offer items at discounts, or have promotions, for rational consumers in order to take sales from their competitors (Bell, Chiang, and Padmanabhan 1999). However, if consumers are loss averse, and not prone to stockpiling, then discounts and promotions have complicated effects once the sale period is over, and consumers can switch to competitors' offerings.

Our data contributes to a fuller picture, based on data ranging from neuroscientific measurement to active markets in housing, consumer products, stocks, and more, about how loss aversion affects economic activity. We also show the first tentative evidence from field data for a "substitution effect" of post-sale effects on substitute products, which invites many other related kinds of empirical exploration. 


\section{REFERENCES}

Arkes, Hal R., Yi-Han Kung, and Laura Hutzel. 2002. "Regret, Valuation, and Inaction Inertia." Organizational Behavior and Human Decision Processes 87 (2): 371-85.

-Bell, David R., J. Chiang, and V. Padmanabhan. 1999. "The Decomposition of Promotional Response: An Empirical Generalization." Marketing Science 18 (4): 504-26.

-Bell, David R., and James M. Lattin. 2000. "Looking for Loss Aversion in Scanner Panel Data: The Confounding Effect of Price Response Heterogeneity." Marketing Science 19 (2): 185-200.

Camerer, Colin, Linda Babcock, George Loewenstein, and Richard Thaler. 1997. "Labor Supply of New York City Cabdrivers: One Day at a Time." Quarterly Journal of Economics 112 (2): 407-41.

Frydman, Cary, and C. F. Camerer. 2014. "A common psychological mechanism generates experienced and anticipatory utility to explain the repurchase effect and disposition effect."
Unpublished.

-Genesove, D., and C. Mayer. 2001. "Loss Aversion and Seller Behavior: Evidence from the Housing Market." Quarterly Journal of Economics 116 (4): 1233-60.

-Kahneman, Daniel, and Amos Tversky. 1979. "Prospect Theory: An Analysis of Decision under Risk." Econometrica 47 (2): 263-92.

- Putler, Daniel S. 1992. "Incorporating Reference Price Effects into a Theory of Consumer Choice." Marketing Science 11 (3): 287-309.

- Thaler, Richard. 1980. "Toward a positive theory of consumer choice." Journal of Economic Behavior \& Organization 1 (1): 39-60.

-Tykocinski, Orit E., and Thane S. Pittman. 2001. "Product Aversion Following a Missed Opportunity: Price Contrast or Avoidance of Anticipated Regret?" Basic and Applied Social Psychology 23 (3): 149-56.

Weber, Martin, and Frank Welfens. 2011. "The follow-on purchase and repurchase behavior of individual investors: An experimental investigation." Die Betriebswirtschaft 71 (2): 139-54. 